\section{Neutropenia associated with paroxetine}

Sir - The lower limit of the normal neutrophil count is $2.5 \times 10^{9} / \mathrm{L}$ except in Afro-Caribbeans and people of Middle Eastern origin where $1.5 \times 10^{9} / \mathrm{L}$ is normal. ${ }^{1} \mathrm{~A}$ number of psychotropic drugs including clozapine, chlorpromazine and thioridazine carry a risk of inducing neutropenia in patients whose white blood counts were previously within the normal range.

Case report

Mrs E is a 38 year old Caucasian lady. She gave a six month history of low mood which was worse in the morning. Her concentration and energy levels were lower than normal. Her libido had decreased and she was unable to look forward to the future with any degree of optimism. She described her appetite and sleeping pattern as normal. The reason for her low mood she put down to the fact that the past three to four years she had been trying unsuccessfully to become pregnant. She felt guilty about this and said that she had let her husband down.

As her mood worsened she began to drink increasing amounts of alcohol but there was no withdrawal phenomena and gradually reduced the amount of alcohol she was consuming to about four units a day. When she had initially seen her family doctor, six months prior to psychiatric referral, he commenced her on paroxetine $20 \mathrm{mg}$ daily which was increased to $40 \mathrm{mg}$ daily.

Unfortunately on the higher dose of paroxetine she developed symptoms of hypomania and so her GP reduced the dose of paroxetine back to $20 \mathrm{mg}$ daily. Although she was somewhat better she still found life difficult to cope with. She also complained of night sweats and numbness in her hands and feet for the last six months.

She has positive family history of psychiatric disorders in that both her mother and older brother have been diagnosed as suffering from depression. Routine blood investigations were normal except for a white blood count (WBC) which was $2.9 \times 10^{9} / \mathrm{L}$ and neutrophils $1.37 \times 10^{9} / \mathrm{L}$. Because of neutropenia paroxetine was discontinued and she kept free of all medications.

Three weeks later white blood cells was $3.1 \times 10^{9} / \mathrm{L}$ with neutrophils at $1.55 \times 10^{9} / \mathrm{L}$. Six weeks later her white blood count was $4.4 \times 10^{9} / \mathrm{L}$ and neutrophils $2.22 \times 10^{9} / \mathrm{L}$. Her general practitioner's records confirmed that all her blood investigations were normal prior to paroxetine prescription when she had seen him initially for her depression.

Paroxetine has been reported to be possibly associated with rapid emergence of severe neutropenia when prescribed to a patient who has been well maintained on clozapine with normal white cell count. ${ }^{2}$ In our case report there is a possibility that paroxetine alone is causing neutropenia.

In conclusion, drug-induced neutropenia is a rare but potentially fatal reaction. It is not usually possible to predict which patients are susceptible and regular routine monitoring of the blood count is only indicated for a few drugs where the risk is known to be significantly higher. Although this case does not allow the conclusion that there is specific risk with paroxetine, we would advise on the need to bear this possibility in mind with patients who get infectious when on paroxetine and also to monitor care- fully those patients to whom paroxetine is prescribed in addition to other drugs known to increase the risk of neutropenia.

Hamdy F Moselhy, Specialist Registrar in General Adult Psychiatry, William Conlon, Consultant Psychiatrist, Bushey Fields Hospital, Bushey Fields Road, Dudley,

West Midlands DY1 2LZ, England.

References

1. Hoffbrand AV, Petit JE. Essential Haematology. 3rd ed. Oxford, Blackwell Scientific Publications; 1993: 156

2. George TP, Innamorato L, Sernyak MJ et al. Leukopenia associated with addition of paroxetine to clozapine (Letter). J Clin Psychiat 1998; 59: 31

\section{The importance of isolated thrombocytopenia on routine blood screening in psychiatric patients}

Sir - Routine blood screening is accepted practice in the investigation and management of psychiatric illness. We present two cases highlighting the importance of base-line blood investigations on admission and of monitoring for potential side-effects where routine full blood count (FBC) revealed isolated thrombocytopenia. We then go on to discuss the relevance of this finding to the management of these patients, in particular relating to the use of neuroleptic medication.

Our first case is a 38 year old man who has a long history of alcohol abuse. He was first admitted in a manic state which was treated with neuroleptic medication. At different times the following drugs were used: haloperidol sulpiride, flupenthixol decanoate and thioridazine, with sedative drugs added at times.

This initial episode was followed by a depressive mood swing and a diagnosis of bipolar affective disorder was made. Blood investigations including a full blood count were relatively normal on admission. His platelet count at this time was $130 \times 10^{9} / \mathrm{ml}$, which was just below the normal range of $150-450 \times 10^{9} / \mathrm{ml}$. However, a repeat FBC two months later showed an isolated low platelet count of $90 \times 10^{9} / \mathrm{ml}$.

We considered that long-standing abuse of alcohol can cause a reduction in platelet count but the lowest count occurred at a time when he was not abusing alcohol. Because of the change in platelet count upon commencement of treatment, neuroleptics were thought to be a possible cause. Neuroleptics were discontinued and treatment with lithium carbonate was successfully instituted. This platelet count remained low for six months after discontinuation of the neuroleptics. The patient remains well and takes lithium carbonite as monotherapy. 